\title{
Danish version of the Oswestry disability index for patients with low back pain. Part 2: Sensitivity, specificity and clinically significant improvement in two low back pain populations
}

\author{
Henrik Hein Lauridsen · Jan Hartvigsen • \\ Claus Manniche · Lars Korsholm • \\ Niels Grunnet-Nilsson
}

Published online: 22 November 2006

(C) Springer-Verlag 2006

Erratum to: Eur Spine J 15:1717-1728

DOI 10.1007/s00586-006-0128-6

Unfortunately in the legend of Fig. 1, the explanations for parts $\mathrm{a}, \mathrm{b}$, and $\mathrm{c}$ were missing in the original article.

The complete legend is given here.

The online version of the original article can be found at http://dx.doi.org/10.1007/s00586-006-0128-6.

H. H. Lauridsen $(\bowtie) \cdot$ J. Hartvigsen · N. Grunnet-Nilsson Institute of Sports Science and Clinical Biomechanics, University of Southern Denmark, Odense, Denmark

e-mail: hlauridsen@health.sdu.dk

H. H. Lauridsen · J. Hartvigsen · C. Manniche .

N. Grunnet-Nilsson

Clinical Locomotion Science, Odense, Denmark

J. Hartvigsen

Nordic Institute for Chiropractic and Clinical Biomechanics,

Odense, Denmark

C. Manniche

Backcenter Funen, Ringe, Denmark

L. Korsholm

Department of Statistics, University of Southern Denmark,

Odense, Denmark 


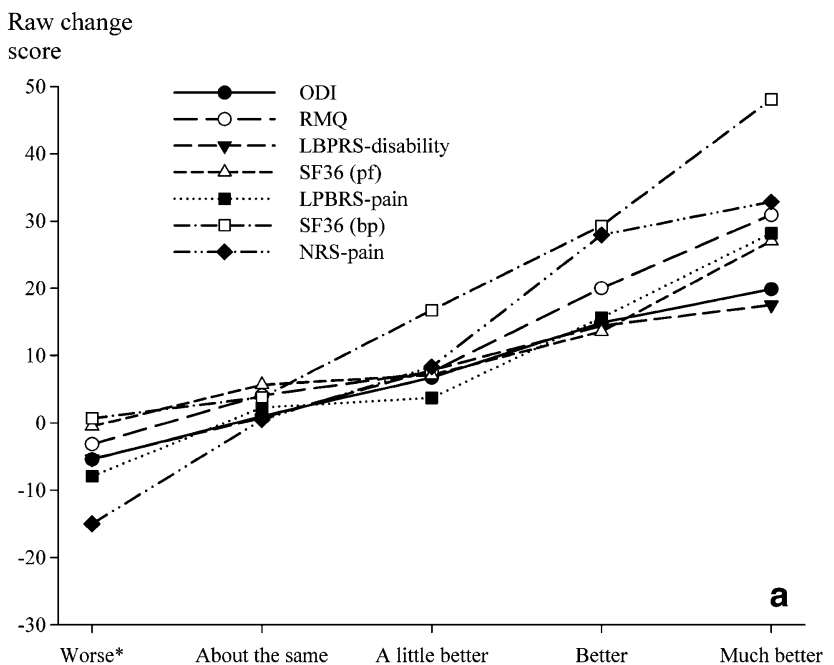

Raw change

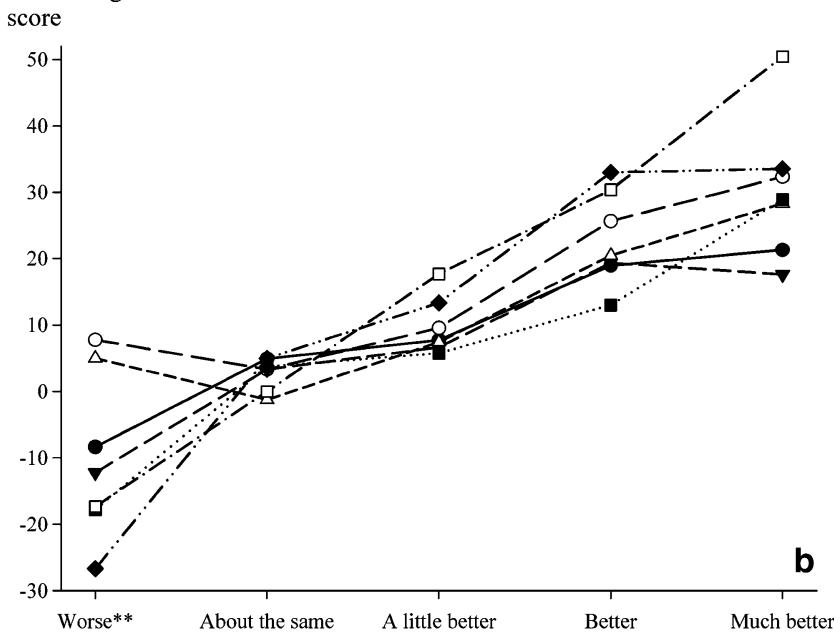

Raw change

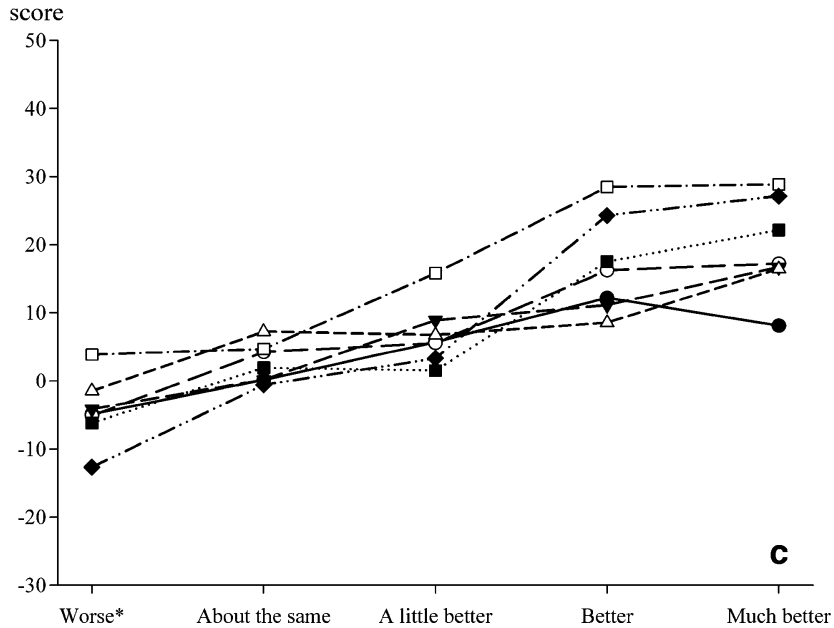

Fig. 1 Mean raw change score for all transition question categories according to where the patient is seen. a all patients; b primary sector patients; c secondary sector patients. * The categories "A little worse", "Worse" and "Much worse" have been collapsed to one category. ** No patients rated themselves as "A little worse" 